\title{
COMPLEXIDADE E TRANSDISCIPLINARIDADE
}

\section{COMPLEXITY AND TRANSDISCIPLINARITY}

\section{COMPLEXIDAD Y TRANSDISCIPLINARIEDAD}

SOMMERMAN, Américo ${ }^{1}$

\begin{abstract}
RESUMO: No auge do reducionismo e da hiperespecialização dele decorrente nas primeiras décadas do século XX, o paradigma da simplicidade da física clássica e as ideias centrais postuladas pela ciência moderna: a da separação total entre o indivíduo observador e objeto observado, a do universo regido pela ordem e obedecendo a lógica aristotélica começam a ser derrogados com a constatação, pelas ciências naturais, da complexidade, da desordem, de lógicas dos sistemas que violavam os princípios da lógica clássica. Além disso, a própria premissa do reducionismo: a existência de um único nível de realidade foi invalidada. $\mathrm{O}$ pensamento reducionista defendia a posição epistemológica de que era possível explicar todos os objetos, fenômenos e sistemas a partir da redução deles à suas partes mais simples e elementares e da compreensão dessas partes. Isso gerou uma hiperespecialização crescente que trouxe perdas, benefícios, transformações e, paradoxalmente, novas aberturas. Nesse contexto, mostraram-se cada vez mais necessários uma razão complexa, que buscasse estabelecer relações entre esses pólos contraditórios, e, também, diálogos cada vez mais amplos entre as disciplinas e entre os saberes. Surgiram, então, o Pensamento Complexo, trabalhando com essa razão complexa, a partir da interseção de várias teorias (teoria da informação, teoria dos sistemas, teoria da auto-organização, teoria do caos) e as abordagens e as metodologias pluri, inter e transdisciplinares.
\end{abstract}

Palavras-chave: Transdisciplinaridade; Interdisciplinaridade; Complexidade; Ciência Moderna.

RESUMEN: En el apogeo del reduccionismo y la especialización resultante en las primeras décadas del siglo XX, el paradigma de la física clásica y la simplicidad de las ideas centrales que postula la ciencia moderna: la separación total entre el observador individual y el objeto observado, el universo se rige por el orden y la obedeciendo a la lógica aristotélica comienza a ser derogada por el hallazgo, las ciencias naturales, la complejidad, el caos, los sistemas lógicos que violan los principios de la lógica clásica. Por otra parte, la premisa misma de reduccionismo: la existencia de un único nivel de realidad ha sido invalidada. El pensamiento reduccionista defendió la posición epistemológica que podría explicar todos los objetos, fenómenos y sistemas reduciéndolos a sus partes más simples y elementales y la comprensión de estas piezas. Esto llevó a una creciente especialización que llevó pérdidas, beneficios,

\footnotetext{
${ }^{1}$ Prof. Dr. em Difusão do Conhecimento, UFBA. Co-criador do Centro de Educação Transdisciplinar (CETRANS), Membro Ativo do Centre International de Recherches et Études Transdisciplinaires (CIRET), email: americosommerman@uol.com.br
} 
transformaciones y, paradójicamente, nuevas aperturas. En este contexto, resultó cada vez más complejo necesita una razón, que buscaba establecer relaciones entre estos dos polos contradictorios, y también cada vez más amplio diálogo entre disciplinas y entre el conocimiento. Surgió el Pensamiento Complejo, el trabajo con este motivo complejo, desde la intersección de varias teorías (teoría de la información, teoría de sistemas, la teoría de la autoorganización, la teoría del caos) y los enfoques y metodologías multi, inter y transdisciplinario.

Palabras-clave: Transdisciplinariedad; Interdisciplinariedad; Complexidad; Ciencia Moderna.

ABSTRACT: At the height of reductionism and specialization resulting in the first decades of the twentieth century, the paradigm of classical physics and simplicity of the central ideas postulated by modern science: the total separation between the individual observer and the observed object, the universe governed by order and obeying Aristotelian logic begin to be derogated with the observation, the natural sciences, complexity, chaos, of logical systems that violated the principles of classical logic. Furthermore, the very premise of reductionism: the existence of a single level of reality has been invalidated. The reductionist thinking defended the epistemological position that could explain all the objects, phenomena and systems by reducing them to their simplest parts and elementary and understanding these parts. This created a increasing specialization which brought losses, benefits, transformations and, paradoxically, new openings. In this context it is necessary a complex reason, which sought to establish relationships between these contradictory poles, and also increasingly broad dialogue between disciplines and between the knowledge. There arose the Complex Thought, working with this complex reason, from the intersection of several theories (information theory, systems theory, theory of self-organization, chaos theory) and the approaches and methodologies multi, inter and transdisciplinary.

Key words: Transdisciplinarity; Interdisciplinarity; Complexity; Modern Science.

\section{INTRODUÇÃO}

No auge do reducionismo e da hiperespecialização dele decorrente nas primeiras décadas do século XX, o paradigma da simplicidade da física clássica e as idéias centrais postuladas pela ciência moderna: a da separação total entre o indivíduo observador e objeto observado, a do universo regido pela ordem e obedecendo a lógica aristotélica começam a ser derrogados com a constatação, pelas ciências naturais, da complexidade, da desordem, de lógicas dos sistemas que violavam os princípios da lógica clássica. Além disso, a própria premissa do reducionismo: a existência de um único nível de realidade, foi invalidada.

O pensamento reducionista defendia a posição epistemológica de que era possível explicar todos os objetos, fenômenos e sistemas a partir da redução deles à suas partes mais 
simples e elementares e da compreensão dessas partes. Isso gerou uma hiperespecialização crescente que trouxe perdas, benefícios, transformações e, paradoxalmente, novas aberturas:

1) A perda de uma visão da globalidade produziu desequilíbrios e destruições no âmbito do sujeito, no da natureza e empobreceu a relação entre ambos.

2) O enorme desenvolvimento tecnológico do século $\mathrm{XX}$ produziu desequilíbrios e destruições, mas também trouxe vários benefícios para uma parte da população mundial.

3) As ciências naturais se desenvolveram de maneira exponencial e encontram dados que derrogavam as ideias fundamentais da ciência moderna e da epistemologia reducionista, gerando novas ideias e conceitos contraditórios, concorrentes e complementares aos que norteavam a ciência.

4) As disciplinas foram conduzidas às fronteiras com as outras disciplina, suscitando transferências de conceitos e de métodos e as abordagens e as metodologias pluri e interdisciplinares, e às fronteiras com o que está além das disciplinas, favorecendo a emergência de metodologias transdisciplinares.

Nesse contexto, mostraram-se cada vez mais necessários uma razão complexa, que buscasse estabelecer relações entre esses pólos contraditórios, e, também, diálogos cada vez mais amplos entre as disciplinas e entre os saberes.

Surgiram, então, o Pensamento Complexo, trabalhando com essa razão complexa, a partir da interseção de várias teorias (teoria da informação, teoria dos sistemas, teoria da autoorganização, teoria do caos) e as abordagens e as metodologias pluri, inter e transdisciplinares.

\section{O PENSAMENTO COMPLEXO}

Vimos que o desenvolvimento das ciências naturais derrogou as três idéias fortes que sustentavam o conhecimento da ciência moderna: "a partir do início do século $[\mathrm{XX}]$ ocorre algo realmente revolucionário no campo da ordem e da certeza: é o surgimento da desordem e da incerteza" (MORIN, 2001, p. 23). A desordem começou a emergir na ciência quando Boltzman enunciou o segundo princípio da termodinâmica, demonstrando que a entropia tende a crescer no universo. Daí surge a tendência para a degradação, para a desordem nos sistemas, uma vez que "no tempo haveria perda da capacidade da energia transformar-se em trabalho" (ibid.). No entanto, isso não instaurou a desordem, pois "foram detectados quatro princípios de organização - o da gravitação, o das interações intracelulares fortes, o das 
interações fracas e o das interações eletromagnéticas" (ibid.). Instaurou-se a presença contínua da ordem e da desordem. Foi um grande golpe no paradigma da simplicidade.

Lupasco, o formulador da lógica do terceiro incluído, lembra que, "se o Segundo Princípio da Termodinâmica estipula que um sistema que não puder receber mais energia do exterior" se degrada em energia térmica ou calor (cf. LUPASCO, s/d, p. 10-11), por outro lado, a energia "manifesta uma heterogeneidade crescente" que foi denominada neguentropia progressiva.

Falando sobre essa idéia de ordem, Ilya Prigogine diz que

La idea de 'leyes de la naturaleza' es probablemente el concepto más original de la ciencia de Occidente. (...) Un rasgo básico de esta ley es su carácter determinista. Una vez conocidas las condiciones iniciales, podemos predecir cualquier posición pasada o futura de una trayectoria. Más aún, la ley de Newton es temporalmente reversible: si a un valor temporal positivo lo reemplazamos por outro negativo, la ley de Newton permanece invariante. (...) Siegue siendo válida esta suposición en nuestros dias? Ha tenido lugar un cambio drástico. Como testimonio de este cambio, citemos la solemne declaración efectuada en 1986 por sir James Lighthill, en ese momento presidente de la Unión Internacional de Mecánica Teórica y Aplicada: 'Aqui debo formular una proposición, hablando nuevamente en nombre de la gran fraternidad mundial de quienes se dedican a la mecánica. Hoy tenemos plena conciencia de que el entusiasmo de nuestros antecesores por los maravillosos logros de la mecánica newtoniana los llevó a hacer ciertas generalizaciones en este área de predictibilidad, en las que en general tendíamos a creer antes de 1960, pero que ahora reconocemos como falsas. Deseamos pedir disculpas colectivas por no haber encaminado en la direción adecuada al público culto en general, difundiendo ideas sobre el determinismo de los sistemas que se atienen a las leyes del movimiento de Newton, ideas que después de 1960 demonstraran ser incorrectas (PRIGOGINE, 2002, p. 38).

Segundo Prigogine, estas desculpas dizem respeito ao descobrimento "da instabilidade dinâmica ou o "caos", que fez com que o conceito de leis determinísticas da natureza tivesse de ser revisto para "incluir a probabilidade e a irreversibilidade".

A idéia do princípio de separação no conhecimento começou a ruir nos anos cinqüenta, com o surgimento do que pode ser chamado de ciências sistêmicas, sobretudo na ecologia, que, a partir da década de trinta, passou a se apoiar no conceito de ecossistema, isto é, "as interações entre os diferentes seres vivos, vegetais, animais, unicelulares” (MORIN, 2001, p. 24), constituindo um fenômeno organizado que, no seu todo, tem "certo número de propriedades que não se encontram nos elementos concebidos isoladamente". O mesmo passa 
a emergir em outras ciências, tais como as ciências da Terra, a cosmologia, e até mesmo a economia. O átomo, as moléculas, a sociedade, o homem são sistemas e sistemas de sistemas. Tudo depende de tudo. Mais uma vez, o paradigma da simplicidade se viu enfraquecido.

A outra separação, entre o observador e o objeto da sua observação, também mostrou sua limitação. "Nenhum ser vivo pode viver sem seu ecossistema, sem seu meio ambiente. Isso quer dizer que não podemos compreender alguma coisa de modo autônomo, senão compreendendo aquilo de que ele é dependente." (ibid., p. 25) Isso também significou uma revolução no pensamento, que, até então, postulava que o conhecimento ideal exigia que se fechasse inteiramente um objeto e, assim isolado, fosse estudado exaustivamente. A nãoseparabilidade entre observador e seu objeto emergiu não apenas na física do interior do átomo, mas também na sociologia e na antropologia. "Não passava de uma ilusão quando acreditávamos eliminar o observador nas ciências sociais. Não é só o sociólogo que está na sociedade; conforme a concepção hologramática, a sociedade também está nele: ele é possuído pela cultura que o possui. Como poderia julgar sua própria sociedade e as outras sociedades?"2 (MORIN, 2000, p 185). A fronteira entre a ciência e a filosofia também vai deixando de ser pertinente em muitas questões fundamentais da ciência de hoje: "quando a ciência física aborda os problemas das origens do universo, esbarramos em questões filosóficas" (MORIN, 2001a, p. 26). "Tudo isso não é só uma volta à modéstia intelectual, também é voltar a uma aspiração autêntica da verdade.” (Ibid., 2000, p. 185)

A idéia da razão apoiada na lógica aristotélica — "a ciência clássica via no aparecimento de uma contradição o sinal de um erro de pensamento e supunha que o universo obedecia à lógica aristotélica" (MORIN, 2000, p. 29) — começou a encontrar seus limites não só nas ciências físicas, com as descobertas dos paradoxos do universo subatômico, mas também com os paradoxos lógicos que emergiram na ciência mais rigorosa - a teoria matemática - com o teorema de Gödel. "O teorema de Gödel nos diz que um sistema de axioma suficientemente rico leva, inevitavelmente, a resultados quer indecidíveis, quer contraditórios.” (NICOLESCU, 2001, p. 58)

Diante desses pares de contraditórios que emergem nesses três pilares do conhecimento da ciência moderna, a ordem, a separabilidade e a razão, Morin sugere que se caminhe em direção a uma razão aberta, que não se restrinja aos princípios da lógica clássica. Não se trata,

\footnotetext{
${ }^{2}$ Mircea Eliade, falando sobre a maneira como os antropólogos e sociólogos estudavam os textos e as obras de outras culturas observa que esses "documentos humanos haviam sido estudados anteriormente com o desinteresse e a indiferença que os naturalistas do século XIX dedicavam ao estudo dos insetos. Agora começase a perceber que esses documentos exprimem situações humanas exemplares, que fazem parte integrante da história do espírito. Ora, o meio apropriado para se apreender o sentido de uma situação humana exemplar não é a 'objetividade' do naturalista, mas a simpatia inteligente do exegeta, do intérprete" (1991, p. 4).
} 
segundo ele, de substituir a ordem pela desordem, a separabilidade pela não-separabilidade, nem a lógica clássica por uma outra lógica ou por uma desrazão.

Apoiando-se então numa razão aberta ou complexa (que busca uma articulação dialógica entre esses pares de contraditórios) e nessas várias teorias: Teoria da Informação (década de 40), Teoria dos Sistemas (também nos anos 40), teorias da auto-organização (década de 70) e a Teoria do Caos (décadas de 70 e 80), foi sendo elaborado o Pensamento Complexo.

Além dessa derrogação das três idéias centrais da ciência moderna: a ordem, a separabilidade e a razão, a premissa do reducionismo: a existência de um único nível de realidade, aquele descrito pela física clássica e percebido pelos cinco sentidos, foi derrubada.

Essa física clássica, que passou ser o modelo da ciência empírico-racional, está fundamentada em duas idéias gerais: (1) a de continuidade: pois de acordo com os órgãos dos sentidos "não se pode passar de um ponto a outro do espaço e do tempo sem passar por todos os pontos intermediários" (NICOLESCU, 2001, p. 18); (2) a de causalidade local: "qualquer fenômeno físico poderia ser compreendido por um encadeamento contínuo de causas e efeitos", sendo que cada causa gera um efeito próximo e cada efeito advém de uma causa próxima. Ambas geram um terceiro conceito, (3) o de determinismo: pois "se soubermos as posições e velocidades dos objetos físicos num dado instante, podemos prever suas posições e velocidades em qualquer outro momento do tempo" (ibid., 19).

Nicolescu observa que a simplicidade e a beleza desses três conceitos fascinaram grande parte dos cientistas e intelectuais dos últimos séculos, que proclamaram a física a rainha da ciência e reduziram toda a realidade ao físico e ao biológico, gerando a ideologia cientificista, que se tornou hegemônica na elite intelectual do século XIX. A conseqüente redução do funcionamento do Universo ao de uma máquina perfeitamente regulada e previsível fez com que todos os outros níveis de realidade e de percepção fossem descartados e o Universo fosse dessacralizado para ser conquistado. Todos os outros níveis da Natureza e do ser humano foram lançados "nas trevas do irracional e da superstição" (ibid., 20) e o sujeito foi transformado em objeto. Essa simplicidade aparente das leis da Natureza gerou uma euforia cientificista que contagiou muitas mentes, que postularam a existência de correspondências entre essas leis e as leis econômicas, sociais e históricas, gerando várias teorias e ideologias mecanicistas e materialistas - como, por exemplo, o marxismo e capitalismo. Essas teorias e ideologias tornaram a idéia "da existência de um único nível de realidade" hegemônica nos ambientes científicos e acadêmicos. 
No entanto, no início do século XX, Max Planck fez uma descoberta que começou a demolir o paradigma científico vigente na época. Ele descobriu que a energia tem uma estrutura descontínua: ela se move por saltos, "sem passar por nenhum ponto intermediário" (ibid., p. 18). Essa descoberta, que derrubou um dos pilares da física clássica, a idéia de continuidade, colocou em questão outro dos seus pilares, a causalidade local. Mas foi apenas na década de 70 que o tipo de causalidade do mundo quântico foi esclarecido e verificado: $a$ causalidade global. No mundo subatômico "as entidades físicas continuam a interagir qualquer que seja o seu afastamento" (ibid., p. 25). Essa comprovação da causalidade global derrogou um dos pilares metodológicos da ciência moderna, a separabilidade (por exemplo, entre sujeito e objeto), e um novo conceito emergiu na física, a não-separabilidade. No entanto, isso não colocou em dúvida a causalidade como um todo, mas mostrou a existência de outro tipo de causalidade, além da local, que não nega a objetividade científica, mas apenas "uma de suas formas: a objetividade clássica, baseada na crença de ausência de qualquer conexão não-local" (ibid., p. 26). Algumas décadas depois da descoberta de Planck, outro dos pais da física quântica, Werner Heisenberg, derrubará o terceiro pilar da física clássica, a idéia de determinismo, pois suas equações mostraram que as entidades quânticas encontradas por Planck (os quanta: os pacotes de energia que se movem por saltos) não podem ser localizados num ponto preciso do espaço e num ponto preciso do tempo. Essas entidades quânticas, muito diferentes dos dois tipos de objetos bem distintos que eram estudados pela física clássica, os corpúsculos e as ondas — pois são as duas coisas ao mesmo tempo —, não podem ter sua trajetória prevista. Portanto, na escala subatômica (o interior do átomo) reina um indeterminismo. No entanto, este não significa acaso ou imprecisão, pois, por um lado, as entidades quânticas não respeitam, como vimos, as idéias fundamentais da física clássica, a continuidade e a causalidade local, e, por outro, as previsões probabilísticas da mecânica quântica são muito precisas no que diz respeito a essas entidades.

Vemos, com isso, que o paradigma da simplicidade da física clássica, que se apoiava na idéia de continuidade, causalidade local e determinismo perdeu seu estatuto ontológico ${ }^{3}$ com a verificação da descontinuidade, da causalidade global e do indeterminismo nas escalas muito pequenas do interior do átomo. Como vimos acima, a física clássica tinha se tornado o paradigma da ciência moderna, que, com isso, viu seu modelo de ciência se transformar.

Além disso, a descoberta de que, no nível das escalas muito pequenas (subatômicas), as leis físicas são diferentes daquelas do nível das escalas macroscópicas invalidou todas as

\footnotetext{
${ }^{3}$ Deixou de ser respaldado na realidade dos seres ou entes (ón, ontos) existentes na natureza e estudados pela ciência.
} 
epistemologias reducionistas (mecanicismo, positivismo, fisicalismo) e seu dogma "da existência de um único nível de Realidade" (ibid., p. 28), hegemônico nas elites intelectuais dos séculos XIX e XX, pois foi comprovada a existência de pelo menos dois níveis de realidade.

Além disso, também na física emergiram vários pares de contraditórios (A e não-A): continuidade e descontinuidade, causalidade local e causalidade global, separabilidade e não-separabilidade, onda e corpúsculo, etc.

\section{INTER E TRANSDISCIPLINARIDADE}

Vimos que, concomitante e paralelamente ao Pensamento Complexo, surgiram as abordagens e metodologias pluri, inter e transdisciplinares para tratar os problemas complexos, muitos deles problemas decorrentes do reducionismo e da hiperespecialização dele resultante.

Encontramos, na definição dos conceitos de multi e de pluridisciplinaridade, uma convergência entre os autores.

A multidisciplinaridade, na prática pedagógica, é a organização mais comum do conhecimento, onde as matérias e as disciplinas se apresentam de maneira independente, sem explicitar as relações entre elas, e, na pesquisa e na resolução de problemas, ela aparece quando se recorre a várias disciplinas, mas sem que isso contribua para modificá-las ou enriquecê-las.

A pluridisciplinaridade é o estabelecimento de relações entre disciplinas mais ou menos afins, com transferência de métodos entre elas, com o enriquecimento do objeto pesquisado, podendo levar à criação de novas disciplinas, mas sem a existência de um verdadeiro diálogo entre os saberes ou entre os especialistas, sem modificá-las internamente de maneira profunda.

Já os conceitos de inter e de transdisciplinaridade são bem mais polissêmicos, de modo que, a partir das definições dos diferentes autores, como Le Moigne ((2002, p. 29), Piaget, Gusdorf, Pineau e de alguns documentos de congressos internacionais ${ }^{4}$ proponho uma categorização que as abarque, as articule e contribua para a pesquisa e para a solução de problemas complexos. Se Nicolescu indicou a existência de diferentes graus de transdisciplinaridade, conforme o nível de satisfação dos três pilares metodológicos da

\footnotetext{
${ }^{4}$ Carta da Transdisciplinaridade (I Congresso Mundial de Transdisciplinaridade, Portugal, 1994) e Síntese do Congresso de Locarno (Congresso Internacional de Transdisciplinaridade, Suíça, 1997).
} 
pesquisa transdisciplinar (cf. 2001, p. 53), a consolidação das diferentes definiçõoes de inter e de transdisciplinaridade permitem que sejam propostos três tipos ou graus para ambos.

Proponho, portanto, a seguinte categorização: interdisciplinaridade de tipo pluridisciplinar, interdisciplinaridade forte e interdisciplinaridade de tipo transdisciplinar; transdisciplinaridade de tipo pluridisciplinar, transdisciplinaridade de tipo interdisciplinar e transdisciplinaridade forte.

A interdisciplinaridade de tipo pluridisciplinar (que também poderia ser chamada de interdisciplinaridade centrífuga ou interdisciplinaridade fraca) aparecerá quando o predominante nas equipes multidisciplinares for a transferência de métodos de uma disciplina para a outra ou "uma série de monólogos justapostos" (GUSDORF, citado por MACHADO, 2000, p. 195).

A interdisciplinaridade forte (ou interdisciplinaridade centrípeta) aparecerá quando o predominante não for a transferência de métodos, mas sim de conceitos, e quando cada especialista não procurar apenas "instruir os outros, mas também receber instrução" e "em vez de uma série de monólogos justapostos", como acontece no caso da interdisciplinaridade de tipo pluridisciplinar, houver "um verdadeiro diálogo" (ibid.), o que requer o favorecimento das trocas intersubjetivas dos diferentes especialistas, onde cada um reconheça em si mesmo e nos outros não só os saberes teóricos, mas os saberes práticos e os saberes existenciais.

A interdisciplinaridade de tipo transdisciplinar aparecerá quando também estiverem presentes nas equipes multidisciplinares "uma modelização epistemológica nova para a compreensão de fenômenos" (LE MOIGNE, 2002, p. 29), e/ou o diálogo com os conhecimentos considerados não científicos (das artes, da filosofia, dos atores sociais, das tradições de sabedoria, etc.) e com os diferentes níveis do sujeito e da realidade.

Poderíamos estabelecer aqui uma subcategoria: interdisciplinaridade fraca ou centrífuga de tipo transdisciplinar: "uma modelização epistemológica nova para a compreensão de fenômenos"; interdisciplinaridade forte ou centrípeta de tipo transdisciplinar: quando nas equipes multidisciplinares também estiverem presentes o diálogo com os conhecimentos considerados não científicos e com os diferentes níveis do sujeito e da realidade.

É importante frisar que a interdisciplinaridade que qualifico de "forte" é forte quanto à ênfase que dá ao sujeito e às trocas intersubjetivas. E a interdisciplinaridade de tipo pluridisciplinar ou centrífuga é chamada aqui de "fraca" no que diz respeito à pouca ênfase que dá ao sujeito. Forte e fraca aqui não indicando nenhum aspecto valorativo.

A transdisciplinaridade de tipo pluridisciplinar se aproxima da interdisciplinaridade de tipo pluridisciplinar, mas se abrindo explicitamente para um diálogo com os saberes não 
disciplinares dos diversos atores sociais (empresas, órgãos públicos, organizações não governamentais).

A transdisciplinaridade de tipo interdisciplinar se aproxima da interdisciplinaridade forte, se abrindo não só para as trocas intersubjetivas dos diferentes especialistas, mas para o diálogo com os saberes dos diversos atores sociais e explicitando a pertinência dos saberes teóricos, dos saberes práticos e dos saberes existenciais ou vivenciais (cf. GALVANI, 1999).

A transdisciplinaridade forte se aproxima da interdisciplinaridade de tipo transdisciplinar, mas se apoia explicitamente nos três pilares da metodologia transdisciplinar (complexidade, níveis de realidade e lógica do terceiro incluído) (cf. A Carta da Transdisciplinaridade e A Síntese do Congresso de Locarno).

Também é importante observar aqui que o qualificativo "forte" é apenas devido à explicitação forte dos três pilares metodológicos da pesquisa transdisciplinar, enquanto a de tipo pluri e a de tipo inter podem não se apoiar neles ou se apoiar apenas num ou dois deles, ou em metodologias e epistemologias menos heurísticas e fortes para o favorecimento de um diálogo ao mesmo tempo rigoroso e aberto entre as disciplinas, os saberes, as culturas, as tradições de sabedoria, etc.

Assim, vemos que entre esses diferentes tipos ou graus de interdisciplinaridade, do mesmo modo que entre eles e os diferentes graus de transdisciplinaridade não há fronteiras estanques, pois em cada um deles sempre há algo do outro e o outro tipo ou grau sempre pode emergir. Dependerá do pólo ou prefixo que se enfatizar, da complexidade menor ou maior do problema que se quiser resolver e dos sujeitos que constituírem o grupo de pesquisa e de ação.

Essa categorização, com observei acima, é a que me parece mais heurística, pois, com ela, podemos manter em movimento a "valsa desses prefixos": o diálogo vivo entre a disciplinaridade, a multidisciplinaridade, a pluridisciplinaridade, e entre os diferentes tipos ou graus de interdisciplinaridade e de transdisciplinaridade.

Sem isso, voltaremos a criar barreiras, feudos, estruturas fechadas, bloqueios no corpo do saber, reduções do olhar, fragmentações do ser e cairemos em impasses semelhantes àqueles disciplinares dos quais temos buscado sair.

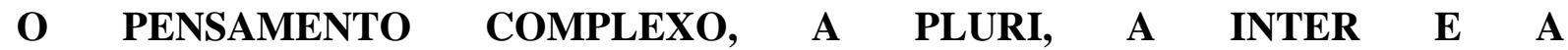 TRANSDISCIPLINARIDADE}

Se considerarmos a etimologia de complexus, "o que é tecido junto" (MORIN, 2001, p. 33), e o Pensamento Complexo que, mediante a razão aberta, articula as polaridades e os 
elementos contraditórios, concorrentes e antagônicos desse "tecido", uma pergunta se impõe: Qual é amplitude dessa articulação? A partir da categorização apresentada no item anterior, podemos localizá-la no âmbito da tessitura da pluridisciplinaridade, da interdisciplinaridade ou da transdisciplinariade?

Dependendo das teorias e saberes que determinado pensamento e razão complexos pretendem articular, mais ampla será a "agulha" (pluri, inter ou transdisciplinar) que utilizará.

Muitas vezes, o pensamento complexo se manifesta com uma transferências de modelos e conceitos da Teoria do Caos (Física de Líquidos) e da Teoria da Auto-organização (Biologia) para a Química, para a Medicina (Epidemologia, Imunologia), para a Economia, mostrando um comportamento complexo dos sistemas pesquisados e resultados aplicáveis no mundo real. Teremos então uma Complexidade de tipo pluridisciplinar ou interdisciplinar, pois se restringe à transferência de modelos e conceitos de uma disciplina para outras.

Um Pensamento Complexo de tipo transdisciplinar forte, por outro lado, propõe uma modelização e uma metodologia muito mais ampla e aberta, que atravessa as disciplinas e vai além delas, incluindo não só os saberes não disciplinares, mas as diferentes culturas, os diferentes níveis do sujeito e os diferentes níveis da realidade.

Dependendo, portanto, da amplitude dessa razão complexa, teremos um tipo ou grau de Pensamento Complexo e um tipo ou grau de transdisciplinaridade.

Podemos, então, definir uma complexidade restrita, uma complexidade ampliada e uma complexidade plena.

A complexidade restrita se manteria nos limites do disciplinar, tecendo as disciplinas científicas, mantendo-se, portanto, no âmbito da interdisciplinaridade de tipo pluridisciplinar ou centrífuga.

A complexidade ampliada iria além das disciplinas, incluindo em sua tessitura não só todos os saberes disciplinares, mas "todas" as dimensões da subjetividade humana: a razão, a emoção, a pulsão; incluindo o lúdico, o irracional e a poesia, enquanto expressões das emoções, sentimentos e intuições humanas. A "agulha" de sua tessitura corresponde, portanto, à interdisciplinaridade forte, que propõe uma inclusão forte do sujeito, e à interdisciplinaridade de tipo transdisciplinar, na qual modelos multidimensionais começam a emergir.

A complexidade plena, de uma natureza transdisciplinar plena, incluiria em sua tessitura não só as disciplinas cientificas, mas as artes, a filosofia, e os saberes e as ciências das 
tradições sapienciais ${ }^{5}$, ou seja, todo o conhecimento produzido ao longo da história humana. Incluiria não só as diferentes dimensões do sujeito, mas a questão ontológica dos diferentes níveis de realidade e dos diferentes níveis do ser humano a eles correspondentes. A "agulha" de sua tessitura corresponderia, portanto, à transdisciplinaridade forte, conforme definida na categorização anterior.

Por se apoiar no Pensamento Complexo e em seus dois princípios de emergência e de imposição ${ }^{6}$, bem como nos três princípios da atitude transdisciplinar (rigor, abertura e tolerância) ${ }^{7}$, este último grau da complexidade, a complexidade plena, nada perderia em rigor ao ser comparada aos dois outros graus, mas ganharia em abertura. Com uma razão complexa articulando as menores partes de cada sistema, os níveis de organização de cada sistema e, em objetos ainda mais complexos, os níveis de realidade do sistema.

Para tanto, essa razão complexa desse Pensamento Complexo Pleno poderia se utilizar dos três pilares da metodologia da pesquisa transdisciplinar definidos acima: 1) níveis de realidade (complementando os níveis de organização da complexidade restrita e da ampliada), 2) lógica do terceiro incluído (complementando a lógica clássica e a dialógica) e 3) complexidade de cada nível de realidade (complementando a complexidade de um cosmo unidimensional do Pensamento Sistêmico e da Complexidade Restrita).

Se, no que diz respeito ao sujeito, o Pensamento Complexo considerar um ser humano razoável e não-razoável (homo sapiens demens) e não só sua dimensão racional (como buscou fazer o reducionismo). Se considerar também a emoção, a pulsão, a intuição e a imaginação, teremos também uma Pensamento Complexo de tipo Transdisciplinar, pois ele poderá ir além das disciplinas. Porém, não chegará a ser uma complexidade plena se considerar no pólo demens o irracional e não abrir o diálogo deste para a possibilidade de um daimôn ${ }^{8}$ supraracional e para o que as tradições sapienciais chamam de Homem Total ou Universal ${ }^{9}$. Será uma complexidade de uma natureza transdisciplinaridade mais restrita, pois não dialogará, de fato, com a quase totalidade das outras culturas: as que viam e vêem o ser humano e o cosmo como multidimensionais.

\footnotetext{
${ }^{5}$ Os níveis sapienciais e iniciáticos das tradições grega, judaica, islâmica, cristã, budista, hindu, das tradições nativas das américas, da África e da Oceania.

${ }^{6} \mathrm{O}$ princípio da emergência diz que o todo é superior à soma das partes e o princípio da imposição diz que o todo é inferior à soma das partes (exemplo: um coral de vozes).

${ }^{7}$ Carta da Transdisciplinaridade, artigo 14.

${ }^{8}$ Para Plotino, o daimôn é sempre o nível logo acima do nível mais ativo de cada ser humano. Se o nível mais ativo for o dos sentidos, o daimôn será a razão $(\log o s)$; se o mais ativo for a razão, o daimôn será a Inteligência (nous); se for a Inteligência, será o espírito (pneuma) e o próprio Deus (cf. PLOTINO, 2002, p. 99)

${ }^{9} \mathrm{O}$ al-Insân al Kâmil (Homem Perfeito ou Universal) da tradição islâmica, o Adam Kadmon (Homem Arquetípico) da tradição judaica, o Anthrôpos Teleios (Homem Perfeito ou Divinisado) da tradição cristão, o Nandjejara (Senhor dos Três Mundos) da tradição tupi, o Cheun-jen (Homem Transcendente) da tradição taoísta.
} 
Chamo essa antropologia e essa cosmologia multidimensionais de tradicional, pois constitui uma invariante cultural: aparece em quase todas as culturas ao longo da história humana. Uma antropologia e uma cosmologia desse tipo também foi o axis mundi, o eixo da cultura ocidental até o século XIII, até a entrada da razão aristotélica nas universidades.

\section{CONSIDERAÇÕES FINAIS}

Precisamos, portanto, propor uma educação que inclua esses três níveis de Pensamento Complexo: complexidade restrita, complexidade ampliada e complexidade plena. Sem isso, não instauraremos um diálogo realmente novo e aberto, pois mesmo a complexidade ampliada não dialoga, de fato, com as outras culturas. Precisamos reencantar a educação e, para isso, a multidimensionalidade é indispensável, pois quanto mais estreita e mais plana é a realidade, menor e mais pobre é o sentido da vida humana.

\section{REFERÊNCIAS BIBLIOGRÁFICAS}

CARTA DA TRANSDISCIPLINARIDADE. In: Educação e transdisciplinaridade. Brasília: UNESCO/USP, 2000. In: O manifesto da transdisciplinaridade. São Paulo: Triom, 2001.

ELIADE, Mircea. Mefistófeles e o andrógino. São Paulo: Martins Fontes, 1991.

GALVANI, Pascal. Fertilization croisée des savoirs et ingenierie d'alternance socioformative: le programe de recherche-formation-action quart monde/université, 1999. In: Transdisciplinarité et Formation. Paris: L'Harmattan, 2005.

LE MOIGNE, Jean-Louis. Legitimer les connaissances interdisciplinaires dans nos cultures, nos enseignements et nos pratiques. In: Ingénierie de l'interdisciplinarité: um nouvel esprit scientifique. Paris: L'Harmattan, 2002.

LUPASCO, Stéphane. O homem e as suas três éticas. Lisboa: Instituto Piaget, [s.d.].

MACHADO, Nílson José. Educação: projetos e valores. São Paulo: Escrituras, 2000.

MORIN, Edgar. Por uma reforma do pensamento. In: $O$ pensar complexo: Edgar Morin e a crise da modernidade. Nascimento, Elimar Pinheiro do; Pena-Veja, Alfredo (orgs.). $3^{\mathrm{a}}$ ed. Rio de Janeiro: Garamond, 2001.

MORIN, Edgar. Ciência com consciência. $4^{\mathrm{a}}$ ed. Rio de Janeiro: Bertrand, 2000.

NICOLESCU, Basarab. O manifesto da transdisciplinaridade. $2^{\mathrm{a}}$ ed. São Paulo: Triom, 2001.

PLOTINO. Tratados das Enéadas. São Paulo: Polar, 2002. 